\title{
Protective effects of Centella asiatica leaf extract on dimethylnitrosamine-induced liver injury in rats
}

\author{
MYUNG-JOO CHOI ${ }^{1 *}$, HONG-MEI ZHENG $^{1 *}$, JAE MIN KIM $^{2}$, KYE WAN LEE $^{3}$, \\ YU HWA PARK ${ }^{3}$ and DON HAENG LEE LE, $^{1,2,4}$ \\ ${ }^{1}$ Department of New Drug Development, College of Medicine; \\ ${ }^{2}$ National Center of Efficacy Evaluation for the Development of Health Products Targeting Digestive Disorders, \\ Inha University Hospital, Incheon 400-712; ${ }^{3}$ Dongkook Pharmaceutical R\&D Center, Gangnam-gu, Seoul 135-502; \\ ${ }^{4}$ Division of Gastroenterology and Hepatology, Inha University Hospital, Incheon 400-712, Republic of Korea
}

Received August 2, 2015; Accepted August 1, 2016

DOI: $10.3892 / \mathrm{mmr} .2016 .5809$

\begin{abstract}
Oxidative stress in liver injury is a major pathogenetic factor in the progression of liver damage. Centella asiatica $(\mathrm{L}$. Urban, known in the United States as Gotu kola, is widely used as a traditional herbal medicine in Chinese or Indian Pennywort. The efficacy of Centella asiatica is comprehensive and is used as an anti-inflammatory agent, for memory improvement, for its antitumor activity and for treatment of gastric ulcers. The present study investigated the protective effects of Centella asiatica on dimethylnitrosamine (DMN)-induced liver injury in rats. The rats in the treatment groups were treated with Centella asiatica at either 100 or $200 \mathrm{mg} / \mathrm{kg}$ in distilled water (D.W) or with silymarin $(200 \mathrm{mg} / \mathrm{kg}$ in D.W) by oral administration for 5 days daily following intraperitoneal injections of $30 \mathrm{mg} / \mathrm{kg}$ DMN. Centella asiatica significantly decreased the relative liver weights in the DMN-induced liver injury group, compared with the control. The assessment of liver histology showed that Centella asiatica significantly alleviated mass periportal \pm bridging necrosis, intralobular degeneration and focal necrosis, with fibrosis of liver tissues. Additionally, Centella asiatica significantly decreased the level of malondialdehyde, significantly increased the levels of antioxidant enzymes, including superoxide dismutase, glutathione peroxidase and catalase, and may have provided protection against the deleterious effects of reactive oxygen species. In addition, Centella asiatica significantly decreased inflammatory mediators, including interleukin (IL)-1 $\beta$, IL-2,
\end{abstract}

Correspondence to: Professor Don Haeng Lee, Department of New Drug Development, College of Medicine, Inha University Hospital, 3-ga, Sinheung dong, Jung-gu, Incheon 400-712, Republic of Korea

E-mail:1dh@inha.ac.kr

*Contributed equally

Key words: liver injury, Centella asiatica, antioxidant enzyme, inflammation
IL-6, IL-10, IL-12, tumor necrosis factor- $\alpha$, interferon- $\gamma$ and granulocyte/macrophage colony-stimulating factor. These results suggested that Centella asiatica had hepatoprotective effects through increasing the levels of antioxidant enzymes and reducing the levels of inflammatory mediators in rats with DMN-induced liver injury. Therefore, Centella asiatica may be useful in preventing liver damage.

\section{Introduction}

Dimethylnitrosamine (DMN) is a representative chemical of a family of $N$-nitroso compounds, and has been found in industrial products. It is a potent hepatotoxin, carcinogen and mutagen (1). DMN exerts carcinogenic effects, central necrosis, inflammation and hemorrhage, and induces hepatic necrosis through metabolic activation by cytochrome P450 2E1 (CYP2E1) in experimental animals $(2,3)$. The activation of nitrosamine by CYP2E1 in the mouse liver stimulates Kuffer cells, leading to the generation of superoxide anion radicals and other reactive oxygen species (ROS) capable of damaging liver cells (4). In addition, single and repeated exposure to DMN causes acute and chronic liver injury leading to necrosis, fibrosis, hypertrophy and nodular regeneration (5-7).

Oxidative stress and ROS, which contribute to the physiological disturbances in the redox status of biological molecules, have been suggested to be closely associated with various pathological conditions (8). ROS induce liver fibrosis, cholestasis, hepatic inflammation and necrosis of liver cells $(9,10)$. These pathologic changes are also responsible for stimulating the production of cytokines, including interleukin (IL)-1 $\beta$, IL-2, IL-4, IL-6, IL-10, IL-12, tumor necrosis factor- $\alpha$ (TNF- $\alpha$ ), interferon- $\gamma$ (IFN- $\gamma$ ) and granulocyte/macrophage colony-stimulating factor (GM-CSF) (11-13). Furthermore, antioxidant enzymes, including superoxide dismutase (SOD), catalase (CAT) and glutathione peroxidase (GPx), may provide protection against the deleterious effects of ROS (14).

Centella asiatica (L.) Urban, known in the United States as Gotu kola, is widely used as a traditional herbal medicine in Chinese or Indian Pennywort. It is a perennial herbaceous creeper of the family Apiaceae and is commonly found in abundance on moist, sandy or clay soils. The efficacy of 
Centella asiatica is comprehensive and has anti-inflammatory effects, improves memory, and has antitumor activity and anti-gastric ulcer effects (15-18). In several studies, Centella asiatica has been reported to have anti-lipid peroxidative and free radical scavenging activities $(19,20)$. Consequently, the present study investigated whether Centella asiatica was capable of preventing DMN-induced liver injury. The investigation focused on functional and morphological improvements through the increasing of anti-oxidant enzymes and attenuation of inflammatory mediators, and evaluating DMN-induced liver injury in a rat model using ethanol (EtOH) extract obtained from Centella asiatica leaves.

\section{Materials and methods}

Preparation of extracts from Centella asiatica. A $20 \mathrm{~g}$ sample of Centella asiatica leaf (Martin Bauer GmbH \& Co. KG, Vestenbergsgreuth, Germany) was extracted using the dipping method in $320 \mathrm{ml}$ of $75 \% \mathrm{EtOH}$ at $30^{\circ} \mathrm{C}$ for $22 \mathrm{~h}$ and filtered using fabric filter. The filtrate was vaporized by an evaporator (Eyela, Tokyo, Japan) at $60^{\circ} \mathrm{C}$ (yield $45 \%$; Brix 54).

Experimental animals. A total of 40 male Sprague-Dawley rats (6-week-old, weighing 180-200 g) were obtained from ORIENT-BIO Laboratory Animal Research Center Co., Ltd. (Gyeonggi-do, Korea). Animal care and all experimental procedures were performed in accordance with the Guide for Animal Experiments by the Korean Academy of Medical Sciences and Inha Research Institute for Medical Sciences (Incheon, Korea; approval ID: INHA 130107-184). All animals were fed standard rat chow with access to tap water ad libitum under $12 \mathrm{~h}$ light-dark cycles at $21^{\circ} \mathrm{C}$.

Animal treatment. The rats were randomly distributed into five experimental groups, each containing eight rats. The treatment groups were treated with Centella asiatica at concentrations of 100 or $200 \mathrm{mg} / \mathrm{kg}$ in distilled water (D.W) or with silymarin (200 mg/kg in D.W.; Sigma-Aldrich; Merck Millipore, Darmstadt, Germany) by oral administration each day for 5 days following intraperitoneal injections of 30 mg/kg DMN (Tokyo Chemical Industry Co., Ltd., Tokyo, Japan). The DMN (vehicle control) group was treated with DMN and equivalent volumes of D.W. The negative control group was treated with saline and D.W. The day following the final administration, all rats were sacrificed under ketamine/xylazine anesthesia, and blood was collected and centrifuged at $1,500 \mathrm{x} \mathrm{g}$ for $10 \mathrm{~min}$ at $4^{\circ} \mathrm{C}$. Liver samples were rapidly obtained and weighed, and biochemical parameters were measured immediately. For the remaining experiments, the serum and liver tissue samples were stored at $-80^{\circ} \mathrm{C}$.

Biochemical analysis. The enzymatic activities and levels of serum aspartate transaminase (AST), alanine transaminase (ALT), albumin, total protein, alkaline phosphatase (ALP), total bilirubin (T-bilirubin), total protein and albumin were analyzed using an auto-analyzer (Beckman Counter AU 480; Beckman Coulter, Fullerton, CA, USA).

Histopathological examinations. For histopathological analyses, the liver tissues were fixed in $10 \%$ buffered formaldehyde and embedded in paraffin. Subsequently, 4-5 $\mu \mathrm{m}$ thick sections were stained with hematoxylin and eosin for histological observation using a light microscope (Olympus Corporation, Tokyo, Japan). The histological observations were scored using a previously described criteria (21).

Liver tissue preparation. The liver tissue from each rat was homogenized in $50 \mathrm{mM}$ of cold potassium phosphate buffer (pH 7.4) containing $1 \mathrm{mM}$ EDTA. The tissue homogenates were sonicated twice at 30 -sec intervals. Homogenization and sonication were performed at $4^{\circ} \mathrm{C}$. Following sonication, the homogenates for lipid peroxidation and biochemical analysis were centrifuged at $13,000 \mathrm{~g}$ for $15 \mathrm{~min}$. Aliquots of the supernatants were used for subsequent experiments.

Levels of malondialdehyde (MDA) in liver tissues. A thiobarbituric acid reactive substance (TBARS) assay kit (ZeptoMetrix Corporation, Buffalo, NY, USA) was used to measure the lipid peroxidation products, MDA equivalents. The formation of lipid peroxides was measured in the homogenates of the hepatic tissues. The formation of MDA, an end product of fatty acid peroxidation, was measured spectrophotometrically at $532 \mathrm{~nm}$ using a TBARS assay, and levels of MDA were expressed as $\mathrm{nmol} / \mathrm{mg}$ tissue.

Levels of SOD in liver tissues. The levels of SOD in the liver tissue homogenates were measured using a commercial kit (Dojindo Laboratories, Kumamoto, Japan) according to the manufacturer's protocol. The assay kit utilizes mitochondrial activity, producing a water-soluble formazan dye upon reduction with the superoxide anion, and the rate of reduction with a superoxide anion is linearly correlated with the activity of xanthine oxidase (XO) and is inhibited by SOD. Thus, the inhibition rate of $\mathrm{XO}$ activity, determined by a colorimetric method, was used to reflect the levels of SOD in the present study. The reaction was measured at an absorbance at $450 \mathrm{~nm}$ on a spectrophotometer, with the levels of SOD expressed as U/mg tissue.

Levels of GPx in liver tissues. The levels of GPx in the liver tissue homogenates were measured using the GPx kit (Enzo Life Sciences, Inc., Farmingdale, NY, USA) according to the manufacturer's protocol. GPx catalyzes the reduction of hydroperoxides, including $\mathrm{H}_{2} \mathrm{O}_{2}$, by reducing glutathione; it functions to protect the cell from oxidative damage. The reaction was measured at an absorbance at $340 \mathrm{~nm}$ on a spectrophotometer, with the levels of GPx expressed as U/mg tissue.

Levels of CAT in liver tissues. The levels of CAT in the liver tissue homogenates were measured using a commercial kit (Cayman Chemical Co., Ann Arbor, MI USA) according to the manufacturer's protocol. Total nitrate/nitrite (NOx), an index of nitric oxide (NO) production, was measured based on the reduction of NOx by vanadium trichloride combined with detection using the acidic Griess reaction according to the method of Miranda et al (22). The reaction was measured at an absorbance at $540 \mathrm{~nm}$ on a spectrophotometer, with the levels of CAT expressed as U/mg tissue.

Levels of serum cytokines. The serum cytokines were measured using a Multi-Analyte ELISArray kit (cat. no. MER-004A; 

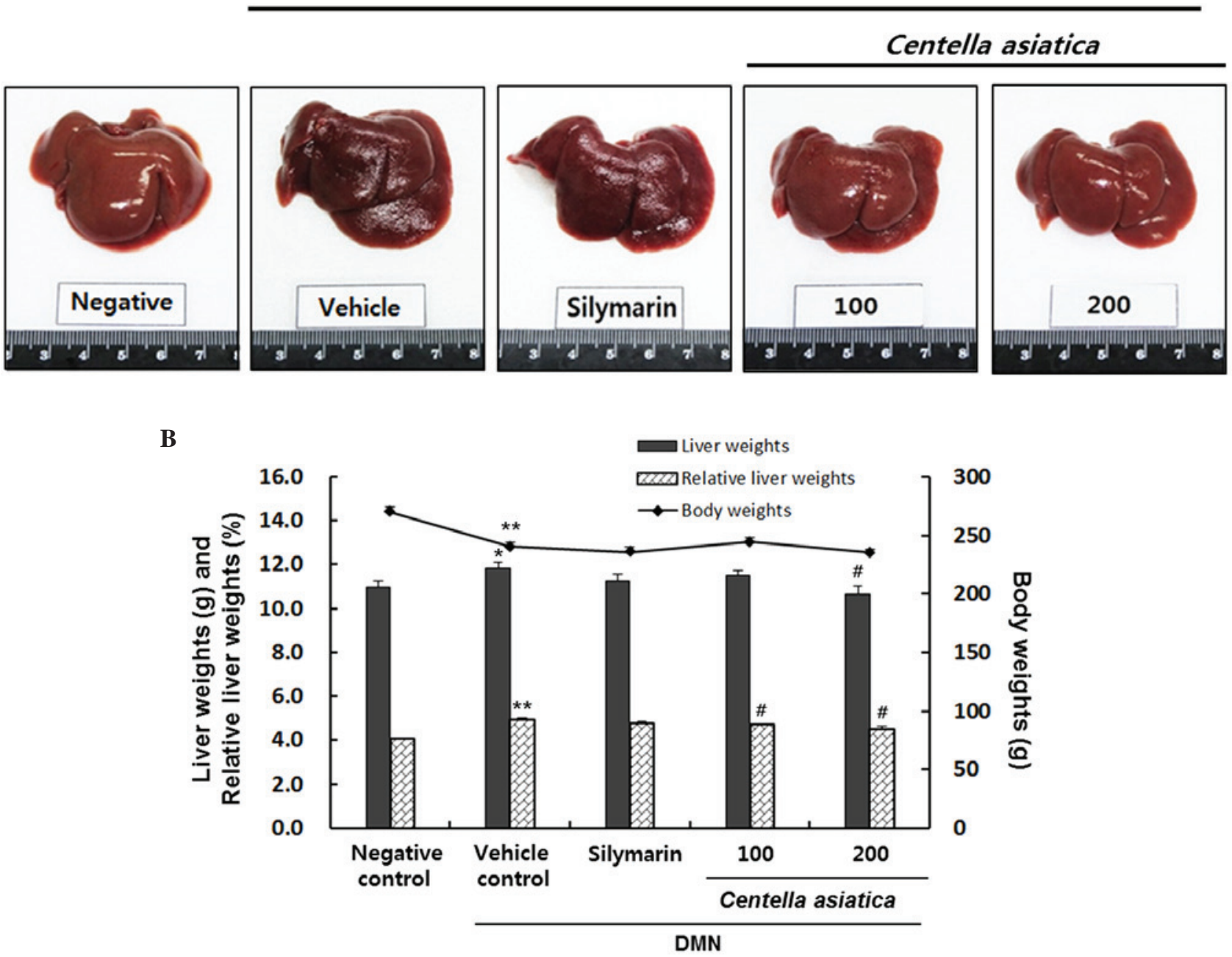

Figure 1. Effects of Centella asiatica on DMN-induced liver injury. (A) Morphological analysis of cells exposed to various treatments against DMN-induced liver injury. Centella asiatica was administered at doses of 100 or $200 \mathrm{mg} / \mathrm{kg}$. (B) Body weights and liver weights. Relative liver weights (\%) were calculated as the liver weight/body weight. Values are presented as the mean \pm standard error of the mean. ${ }^{* *} \mathrm{P}<0.01$ and ${ }^{*} \mathrm{P}<0.05$, compared with the negative control; ${ }^{\text {"}} \mathrm{P}<0.05$, compared with the vehicle control. DMN dimethylnitrosamine.

SABiosciences; Qiagen, Inc, Valencia, CA, USA) according to the manufacturer's protocol. Samples were added to the array, which included the following specific cytokine capture antibodies from the above-mentioned kit: IL-1 $\beta$, IL-2, IL-4, IL-6, IL-10, IL-12, TNF- $\alpha$, IFN- $\gamma$ and GM-CSF. The reaction was measured by changes at 450 and $540 \mathrm{~nm}$ on a spectrophotometer.

Statistical analysis. All values are expressed as the mean \pm standard error of the mean. The statistical significance of differences among groups were examined using a Mann-Whitney $\mathrm{U}$ test. $\mathrm{P}<0.05$ was considered to indicate a statistically significant difference. Statistical calculations were performed using SPSS software for the MS Windows operating system (Version 19.0; IBM SPSS, Armonk, NY, USA).

\section{Results}

Effects of Centella asiatica on gross morphology, body weights, liver weights and relative liver weights in rats with $D M N$-induced liver injury. As shown in Fig. 1A, the surface of the negative control liver tissue was smooth and brown with an evident gloss and a soft texture. By contrast, the surface of the vehicle control liver tissue was rough and reddish-brown, and the texture was hard. In addition, treatment with DMN significantly decreased the body weights of the rats, by $\sim 89 \%$, compared with the rats in the negative control group (Fig. 1B). This result is in contrast with the vehicle control group, in which the liver weights and relative liver weights were increased by 7.6 and $20.9 \%$, respectively (liver weight: $11.0 \pm 0.26$, vs. $11.8 \pm 0.28 \mathrm{~g}$; relative liver weight: $4.1 \pm 0.05$, vs. $4.9 \pm 0.08 \%)$. The results showed that Centella asiatica decreased the liver weights by $11.5 \pm 0.22 \mathrm{~g}$ and $10.6 \pm 0.37 \mathrm{~g}$ at doses of 100 and $200 \mathrm{mg} / \mathrm{kg}$, respectively. In particular, $200 \mathrm{mg} / \mathrm{kg}$ of Centella asiatica significantly decreased liver weights, and significantly decreased relative liver weights by $4.7 \pm 0.04$ and $4.5 \pm 0.11 \%$ at doses of 100 and $200 \mathrm{mg} / \mathrm{kg}$, respectively.

Effects of Centella asiatica on serum cytokine levels in rats with DMN-induced liver injury. The effects of Centella asiatica on DMN-induced liver injury were evaluated 
A

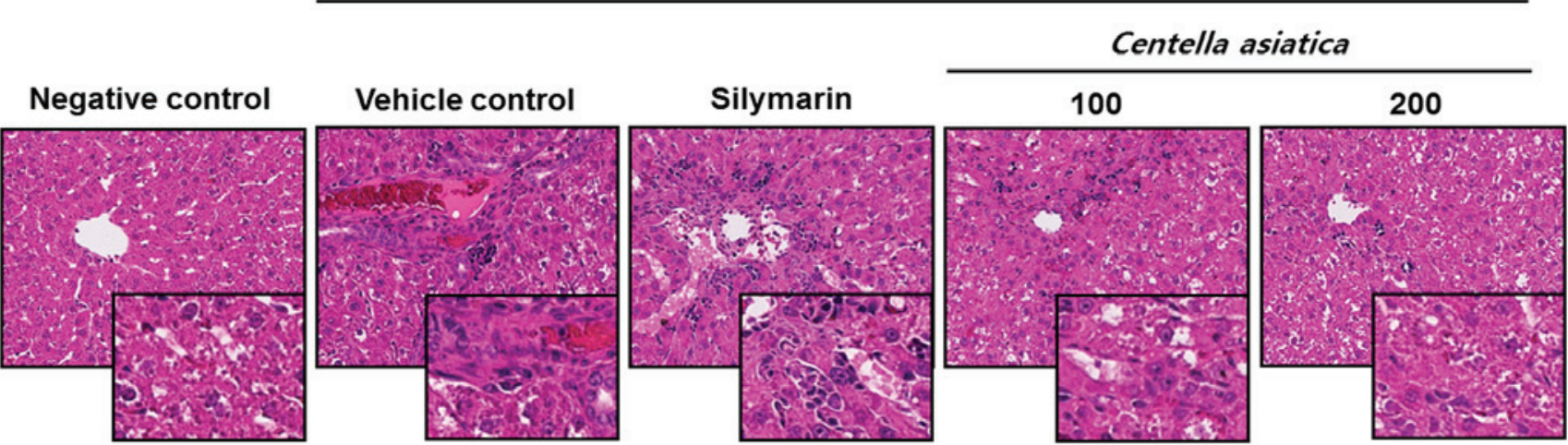

$\mathbf{B}$
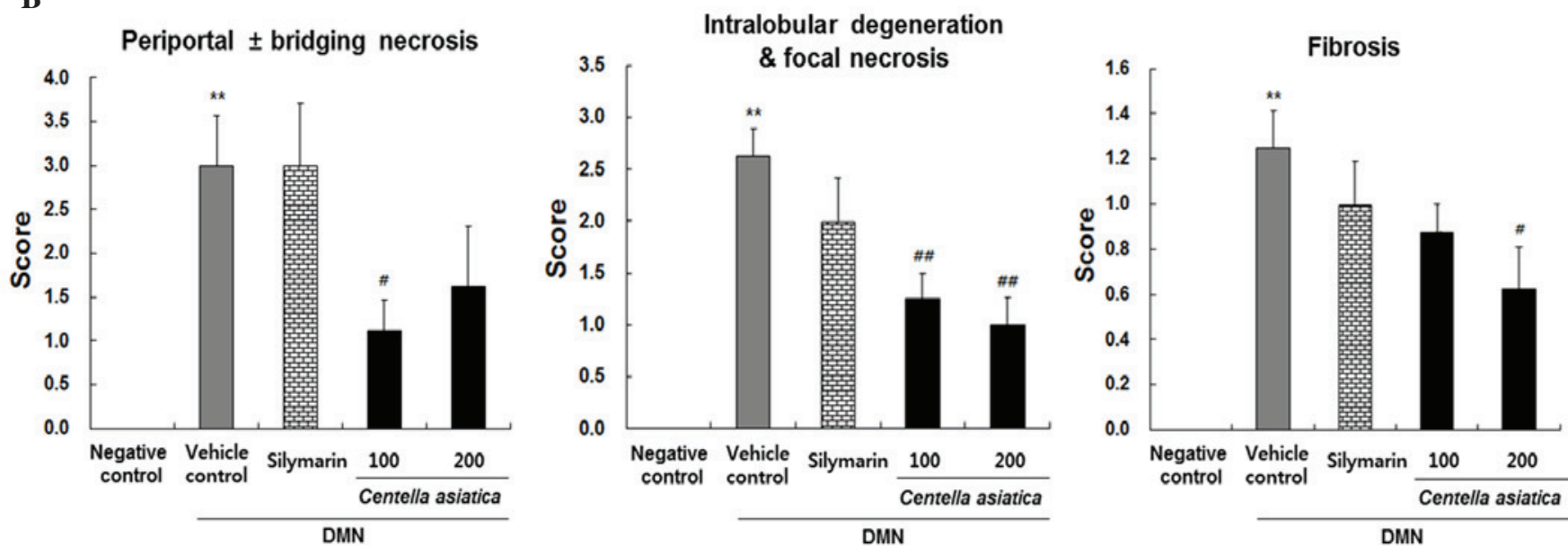

Figure 2. Effects of Centella asiatica on DMN-induced changes in liver histology. (A) Representative images at magnification, x200 and x400 (insert), (B) Histological activity scores for periportal \pm bridging necrosis, intralobular degeneration and focal necrosis, and fibrosis. Animals ( $\mathrm{n}=8 / \mathrm{group}$ ) were orally administered with Centella asiatica at 100 or $200 \mathrm{mg} / \mathrm{kg}$. The vehicle control comprised DMN with distilled water. Values are presented as the mean \pm standard error of the mean. ${ }^{* *} \mathrm{P}<0.01$, compared with the negative control: ${ }^{\# *} \mathrm{P}<0.01$ and ${ }^{\#} \mathrm{P}<0.05$, compared with the vehicle control. DMN dimethylnitrosamine.

by determining the levels of AST, ALT, ALP, T-bilirubin, total protein and albumin. As shown in Table I, the levels of AST (145.2 $\pm 4.5 \mathrm{IU} / \mathrm{l}), \operatorname{ALT}(72.9 \pm 4.0 \mathrm{IU} / \mathrm{l}), \operatorname{ALP}(694.1 \pm 27.5 \mathrm{IU} / \mathrm{l})$ and T-biliubin $(0.281 \pm 0.018 \mathrm{mg} / \mathrm{dl})$ were significantly elevated following DMN treatment, compared with the negative

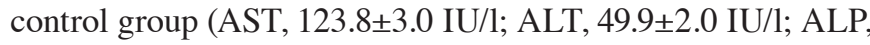
$466.0 \pm 18.7 \mathrm{IU} / \mathrm{l}$; T-biliubin, $0.110 \pm 3.0 \mathrm{mg} / \mathrm{dl})$. By contrast, Centella asiatica ameliorated this increase significantly for AST, ALT, ALP and T-biliubin, compared with the vehicle control group. Silymarin significantly decreased the levels of

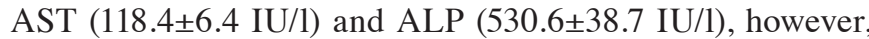
no significant changes in ALT $(68.1 \pm 3.9$ IU/1) or T-biliubin $(0.269 \pm 0.019 \mathrm{mg} / \mathrm{dl})$ were observed.

Histologic analysis of the effects of Centella asiatica in rats with DMN-induced liver injury. Representative histological images of the pancreas are shown in Fig. 2A and the quantitative histological scoring of periportal \pm bridging necrosis, intralobular degeneration and focal necrosis, and fibrosis are shown in Fig. 2B. The liver tissue from the vehicle control group induced by DMN showed significant increases in mass periportal \pm bridging necrosis, intralobular degeneration and focal necrosis, and fibrosis. By contrast, Centella asiatica reduced the periportal \pm bridging necrosis at the dose of $200 \mathrm{mg} / \mathrm{kg}$, and a significant effect was shown in the rats treated with $100 \mathrm{mg} / \mathrm{kg}$. Centella asiatica also significantly decreased intralobular degeneration and focal necrosis at the doses of 100 and $200 \mathrm{mg} / \mathrm{kg}$. Centella asiatica reduced liver fibrosis at the dose of $100 \mathrm{mg} / \mathrm{kg}$, and a significant effect was shown in the rats treated with $200 \mathrm{mg} / \mathrm{kg}$. However, treatment with silymarin caused no significant improvements in periportal \pm bridging necrosis, intralobular degeneration and focal necrosis or fibrosis. These results suggested that Centella asiatica led to reductions in liver tissue damage, which was characterized by significant amelioration of liver injury, measured by histological scores, compared with those of the vehicle control group.

Effects of Centella asiatica on hepatic levels of MDA, SOD, GPX and CAT in rats with DMN-induced liver injury. Oxidative stress was quantified through the levels of MDA, SOD, GPx and CAT in liver tissue homogenates, as indicators of lipid peroxidation and antioxidant enzyme activity. As shown in Fig. 3A, the level of MDA was markedly increased to $0.5 \pm 0.1 \mathrm{nmol} / \mathrm{mg}$ tissue in the vehicle control group. However, Centella asiatica significantly decreased the level of MDA to $0.3 \pm 0.03 \mathrm{nmol} / \mathrm{mg}$ and $0.2 \pm 0.01 \mathrm{nmol} / \mathrm{mg}$ tissue at the doses of 100 and $200 \mathrm{mg} / \mathrm{kg}$, respectively. The effect of $200 \mathrm{mg} / \mathrm{kg}$ of Centella asiatica was more marked, compared with that of silymarin. The level of SOD in the liver in the vehicle control 
Table I. Effects of Centella asiatica on serum parameters in rata with DMN-induced liver injury.

\begin{tabular}{|c|c|c|c|c|c|}
\hline \multirow[b]{3}{*}{ Parameter } & \multirow[b]{3}{*}{ Negative control } & \multicolumn{4}{|c|}{$\mathrm{DMN}$} \\
\hline & & \multirow[b]{2}{*}{ Vehicle control } & \multirow[b]{2}{*}{ Silymarin } & \multicolumn{2}{|c|}{ Centella asiatica $(\mathrm{mg} / \mathrm{kg})$} \\
\hline & & & & 100 & 200 \\
\hline AST (IU/l) & $123.8 \pm 3.0$ & $145.2 \pm 4.5^{\mathrm{a}}$ & $118.4 \pm 6.4^{b}$ & $108.3 \pm 5.9^{b}$ & $99.2 \pm 3.7^{b}$ \\
\hline ALT (IU/l) & $49.9 \pm 2.0$ & $72.9 \pm 4.0^{\mathrm{a}}$ & $68.1 \pm 3.9$ & $66.8 \pm 3.4$ & $58.0 \pm 2.4^{\mathrm{b}}$ \\
\hline ALP (IU/l) & $466.0 \pm 18.7$ & $694.1 \pm 27.5^{\mathrm{a}}$ & $530.6 \pm 38.7^{\mathrm{b}}$ & $556.4 \pm 39.6^{\mathrm{c}}$ & $495.3 \pm 27.0^{\mathrm{b}}$ \\
\hline T-biliubin (mg/dl) & $0.110 \pm 0.008$ & $0.281 \pm 0.018^{\mathrm{a}}$ & $0.269 \pm 0.019$ & $0.241 \pm 0.016$ & $0.224 \pm 0.012^{c}$ \\
\hline Total protein $(\mathrm{g} / \mathrm{dl})$ & $5.9 \pm 0.2$ & $6.07 \pm 0.09$ & $5.56 \pm 0.12$ & $5.85 \pm 0.12$ & $5.80 \pm 0.08$ \\
\hline Albumin (g/dl) & $3.3 \pm 0.1$ & $3.41 \pm 0.05$ & $3.16 \pm 0.06$ & $3.29 \pm 0.06$ & $3.25 \pm 0.04$ \\
\hline
\end{tabular}

Values are presented as the mean \pm standard error of the mean. ${ }^{\mathrm{a}} \mathrm{P}<0.01$, compared with the negative control; ${ }^{\mathrm{b}} \mathrm{P}<0.01$ and ${ }^{\mathrm{c}} \mathrm{P}<0.05$, compared with the vehicle control. Negative control, saline+D.W treatment; Vehicle control, DMN+D.W treatment; Silymarin, DMN+200 mg/kg silymarin; $100, \mathrm{DMN}+100 \mathrm{mg} / \mathrm{kg}$ Centella asiatica; 200, DMN+200 mg/kg Centella asiatica. DMN dimethylnitrosamine; AST, aspartate aminotransferase; ALT, alanine aminotransferase; ALP, alkaline phosphatase; T-Bilirubin, total bilirubin; D.W, distilled water.

A

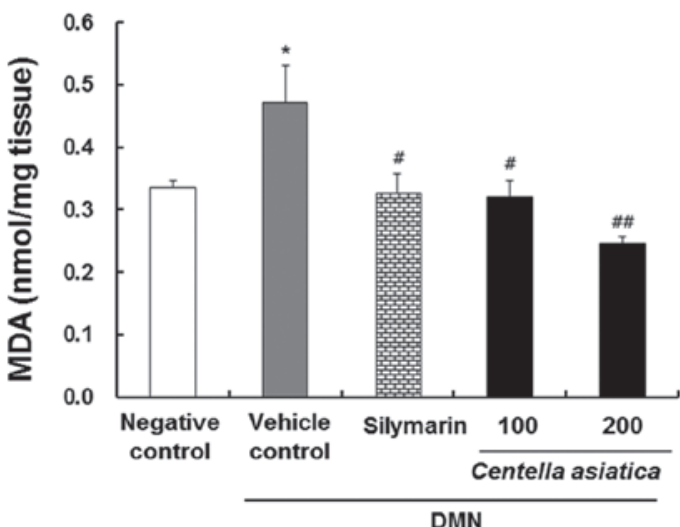

C

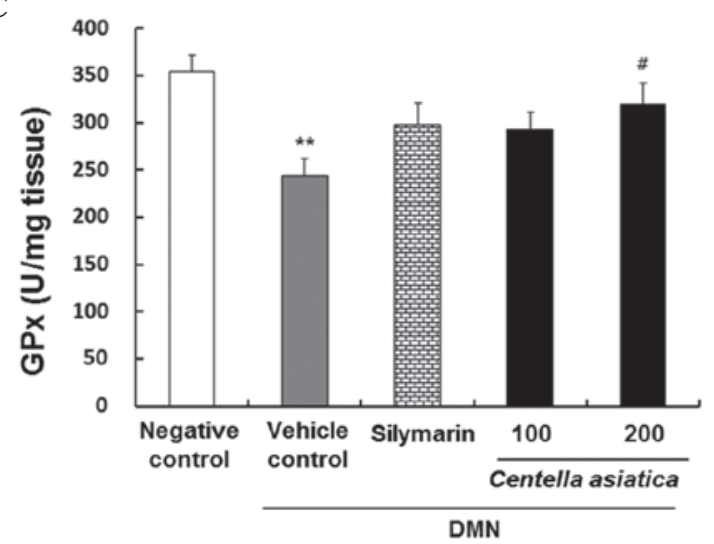

B

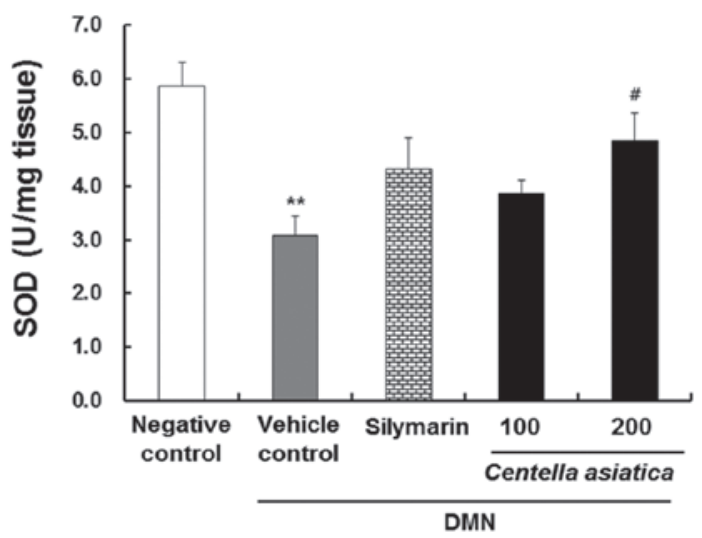

D

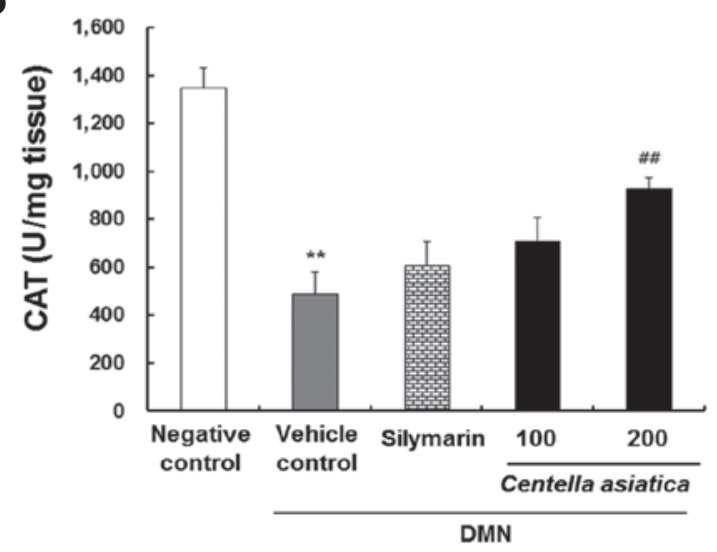

Figure 3. Effects of Centella asiatica on DMN-induced hepatic levels in liver tissue. (A) MDA (nmol/mg tissue), (B) SOD (U/mg tissue), (C) GPx (U/mg tissue) and (D) CAT (U/mg tissue). The animals (n=8/group) were orally administrated with Centella asiatica at $100 \mathrm{or} 200 \mathrm{mg} / \mathrm{kg}$. DMN in D.W was used as a vehicle control. Saline in D.W was used as a negative control. Values are presented as the mean \pm standard error of the mean. ${ }^{* *} \mathrm{P}<0.01$ and ${ }^{*} \mathrm{P}<0.05$, compared with the negative control; ${ }^{\# \#} \mathrm{P}<0.01$ and ${ }^{\#} \mathrm{P}<0.05$, compared with the vehicle control. DMN, dimethylnitrosamine; MDA, malondialdehyde; SOD, superoxide dismutase; GPx, glutathione peroxidase; CAT, catalase; D.W, distilled water.

group was significantly lower, compared with that in the negative control group, whereas the level of SOD level in the $200 \mathrm{mg} / \mathrm{kg}$ Centella asiatica treated group was 1.6-fold higher, compared with that in the vehicle control group (Fig. 3B). In addition, the level of GPx in the liver was markedly decreased to $243.7 \pm 18.9 \mathrm{U} / \mathrm{mg}$ tissue in the vehicle control group; however, Centella asiatica increased the level of GPx at a dose of $100 \mathrm{mg} / \mathrm{kg}$, with a significant effect in the rats treated with $200 \mathrm{mg} / \mathrm{kg}$ (Fig. 3C). Furthermore, the levels of CAT in the liver decreased considerably to $485.6 \pm 92.6 \mathrm{U} / \mathrm{mg}$ tissue in the 

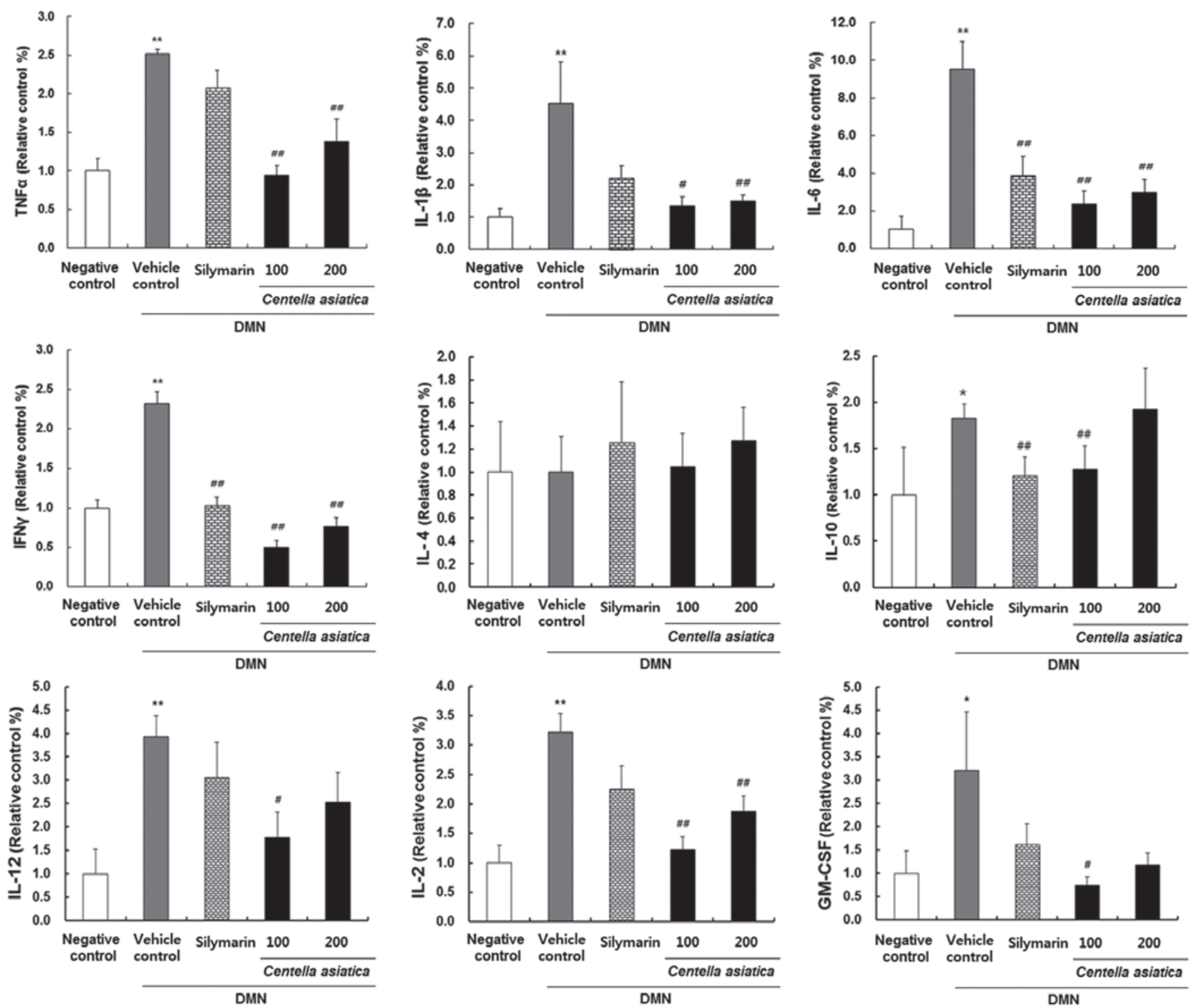

Figure 4. Effect of Centella asiatica on DMN-induced inflammatory cytokines and mediators in serum. The animals ( $\mathrm{n}=8 / \mathrm{group}$ ) were orally administrated with Centella asiatica at 100 or $200 \mathrm{mg} / \mathrm{kg}$. DMN in D.W was used as a vehicle control. Saline in D.W was used as a negative control. Values are presented as the mean \pm standard error of the mean. ${ }^{* *} \mathrm{P}<0.01$ and ${ }^{*} \mathrm{P}<0.05$, compared with the negative control; ${ }^{* \#} \mathrm{P}<0.01$ and ${ }^{\#} \mathrm{P}<0.05$, compared with the vehicle control. DMN, dimethylnitrosaminel TNF, tumor necrosis factor- $\alpha$; TNF- $\alpha$; IL, interleukin; IFN- $\gamma$, interferon- $\gamma$; GM-CSF, granulocyte/macrophage colony-stimulating factor; D.W, distilled water.

vehicle control group. However, Centella asiatica increased the level of CAT at a dose of $100 \mathrm{mg} / \mathrm{kg}$ and had a significant effect in the rats treated with $200 \mathrm{mg} / \mathrm{kg}$ (Fig. 3D).

Effects of Centella asiatica on cytokine levels in rats with DMN-induced liver injury. To identify whether Centella asiatica had an effect on inflammation, the present study investigated the cytokine levels of IL-1 $1 \beta$, IL-2, IL-4, IL-6, IL-10, IL-12, TNF- $\alpha$, IFN- $\gamma$ and GM-CSF in rats with DMN-induced liver injury. As shown in Fig. 4, the cytokine levels of TNF- $\alpha$, IL-1 $\beta$, IL-6, IFN- $\gamma$, IL-10, IL-12, IL-2 and GM-CSF were significantly elevated in the vehicle control group, compared to the negative control group. When the rats were treated with 100 or $200 \mathrm{mg} / \mathrm{kg}$ Centella asiatica, the levels of TNF- $\alpha$, IL-1 $\beta$, IL-6, IFN- $\gamma$, IL-10, IL-12, IL-2 and GM-CSF were significantly decreased, compared with those in the vehicle control group.

\section{Discussion}

DMN is reported to be involved in liver necrosis and carcinogenesis, exhibited through a number of mechanisms (23). The present study showed that Centella asiatica had a protective effect against liver injury induced by DMN.

In the present study, no significant changes in body weights were observed in the different experimental groups, with the exception of the vehicle control. The measurement of the relative liver weights provides a more accurate approach to demonstrate the changes in liver size, compared with the measurement of liver weights alone, as the liver weight depends primarily on the size of the rat (24). The enlargement of the livers in the DMN-treated rats signified hepatic lesions and liver damage associated with the induction of injury by DMN. These significant changes in the liver weights may be attributed to the accumulation of collagen and extracellular 
matrix protein in liver tissue (25). In the present study, liver enlargement was significantly reduced in the rats treated with Centella asiatica.

Hepatocellular damage is evidenced by marked elevation in the activities of serum AST, ALT, ALP and T-bilirubin. Serum AST, ALT, ALP and T-bilirubin are the most sensitive markers used in the diagnosis of liver damage as they are cytoplasmic in location and are leaked into the circulation following cellular injury (26).

Among the serum liver biomarkers, ALT and AST are considered to be indicators of hepatotoxic effects, where their elevation is considered as a more sensitive indicator. The levels of enzymes, which leak into the blood stream indicate the severity of hepatic injury $(27,28)$. In the present study, the rats with DMN-induced liver injury were found to have significantly higher serum biomarker levels, compared with the negative control rats. However, Centella asiatica exhibited hepatoprotective effects by attenuating the elevated serum parameters.

ROS, the natural byproducts of oxidative energy metabolism, are considered to be a physiologic modulator of a number of intracellular signaling pathways (29). Therefore, the defense mechanisms against oxidative damage are an important element of the cellular stress response, during which a diverse array of electrophilic and oxidative toxicants can be either eliminated or inactivated prior to them causing damage critical macromolecules (30). In addition, the enhancement of oxidative stress and the peroxidation process have been implicated in DMN-induced liver injury in rats (31).

Centella asiatica has been reported to enhance antioxidant enzymes, including SOD, GPx and CAT in adriamycin-induced cardiomyopathy and pentylenetetrazole-induced oxidative stress, and in experimentally induced parkinsonism in rats (32-34). As expected, the present study demonstrated that Centella asiatica increased the levels of SOD, GPx and CAT with concomitant decreases in the level of MDA in rats with DMN-induced liver injury.

ROS are important cytotoxic and signaling mediators in the pathophysiology of inflammatory liver injury (35). Among those, pro-inflammatory and fibrogenic responses are mediated by the action of cytokines, including IL-1 $\beta$, IL-6 and TNF- $\alpha$ (36). In addition, IFN- $\gamma$ is reported to be involved in various types of inflammatory diseases (37). A study by Zoheir et al reported that treatment with DMN alone caused a significant increase in the expression of IFN- $\gamma$ (38). In addition, a study by Thompson et al (39) reported that IL-10 is expressed during macrophage activation in liver injury, and that IL-10 is capable of downregulating various aspects of pro-inflammatory macrophage function. The enhanced production of IL-2 and IL-12 are also involved in cell-mediated cytotoxic activity (40-42) and GM-CSF can induce the secretion of IL-1 and TNF- $\alpha$ cytokines (43). In the present study, Centella asiatica decreased the expression of proinflammatory cytokines, including IL- $1 \beta$, IL-6, TNF- $\alpha$, and other inflammatory cytokines and mediators in parallel with decreasing the levels of inflammatory cytokines in DMN-induced liver injury. Histologically, DMN administration in the present study produced severe periportal \pm bridging necrosis, intralobular degeneration and focal necrosis, and fibrosis in the liver tissues, whereas Centella asiatica ameliorated hepatocyte necrosis and fibrosis in the rats with $\mathrm{DMN}$-induced liver injury.

In conclusion, the present study demonstrated that Centella asiatica exhibited hepatoprotective effects through increasing the levels of antioxidant enzymes and reducing the levels of inflammatory mediators in rats with DMN-induced liver injury. Therefore, Centella asiatica may be useful in preventing liver damage in the future.

\section{Acknowledgements}

This study was supported by grants from the Korean Health Industry Development Institute and the National Center of Efficacy Evaluation for the Development of Health Products Targeting Digestive Disorders (grant no. HI15C0989).

\section{References}

1. George J, Rao KR, Stern R and Chandrakasan G: Dimethylnitrosamine-induced liver injury in rats: The early deposition of collagen. Toxicology 156: 129-138, 2001.

2. Guengerich FP, Kim DH and Iwasaki M: Role of human cytochrome P-450 IIE1 in the oxidation of many low molecular weight cancer suspects. Chem Res Toxicol 4: 168-179, 1991.

3. Jin YL, Enzan H, Kuroda N, Hayashi Y, Nakayama H, Zhang YH, Toi M, Miyazaki E, Hiroi M, Guo LM and Saibara T: Tissue remodeling following submassive hemorrhagic necrosis in rat livers induced by an intraperitoneal injection of dimethylnitrosamine. Virchows Arch 442: 39-47, 2003.

4. Teufelhofer O, Parzefall W, Kainzbauer E, Ferk F, Freiler C, Knasmüller S, Elbling L, Thurman R and Schulte-Hermann R: Superoxide generation from kupffer cells contributes to hepatocarcinogenesis: Studies on NADPHoxidase knockout mice. Carcinogenesis 26: 319-329, 2005.

5. Wills PJ, Suresh V, Arun M and Asha VV: Antiangiogenic effect of lygodium flexuosum against $\mathrm{N}$-nitrosodiethylamine-induced hepatotoxicity in rats. Chem Biol Interact 164: 25-38, 2006.

6. Pradeep K, Mohan CV, Gobianand K and Karthikeyan S: Effect of Cassia fistula linn. Leaf extract on diethylnitrosamine induced hepatic injury in rats. Chem Biol Interact 167: 12-18, 2007.

7. Jayakumar S, Madankumar A, Asokkumar S Raghunandhakumar S, Gokula dhas K, Kamaraj S, Divya MG and Devaki T: Potential preventive effect of carvacrol against diethylnitrosamine-induced hepatocellular carcinoma in rats. Mol Cell Biochem 360: 51-60, 2012.

8. Caro AA and Cederbaum AI: Oxidative stress, toxicology and pharmacology of CYP2E1. Annu Rev Pharmacol Toxicol 44: 27-42, 2004.

9. Cressman DE, Greenbaum LE, DeAngelis RA, Ciliberto G, Furth EE, Poli V and Taub R: Liver failure and defective hepatocyte regeneration in interleukin-6-deficient mice. Science 274: 1379-1383, 1996.

10. Tilg $\mathrm{H}$ and Diehl AM: Cytokines in alcoholic and nonalcoholic steatohepatitis. N Engl J Med 343: 1467-1476, 2000.

11. Guan L, Fu PY, Li PD, Li ZN, Liu HY, Xin MG and Li W: Mechanisms of hepatic ischemia-reperfusion injury and protective effects of nitric oxide. World J Gastrointest Surg 6: 122-128, 2014.

12. Schümann J, Prock1 J, Kiemer AK, Vollmar AM, Bang R and Tiegs G: Silibinin protects mice from $\mathrm{T}$ cell-dependent liver injury. J Hepatol 39: 333-340, 2003.

13. Radaeva S, Sun R, Jaruga B, Nguyen VT, Tian Z and Gao B: Natural killer cells ameliorate liver fibrosis by killing activated stellate cells in NKG2D-dependent and tumor necrosis factor-related apoptosis-inducing ligand-dependent manners. Gastroenterology 130: 435-452, 2006.

14. Halliwell B and Gutteridge JM: Role of free radical and catalytic metal ions in human disease: An overview. Methods Enzymol 186: 1-85, 1990.

15. Suguna L, Sivakumar P and Chandrakasan G: Effects of Centella asiatica extract on dermal wound healing in rats. Indian J Exp Biol 34: 1208-1211, 1996. 
16. Veerendra Kumar MH and Gupta YK: Effect of different extracts of Centella asiatica on cognition and markers of oxidative stress in rats. J Ethnopharmacol 79: 253-260, 2002.

17. Babu TD, Kuttan G and Padikkala J: Cytotoxic and anti-tumour properties of certain taxa of umbelliferae with special reference to Centella asiatica (L.) urban. J Ethnopharmacol 48: 53-57, 1995.

18. Sairam K, Rao CV and Goel RK: Effect of Centella asiatica linn on physical and chemical factors induced gastric ulceration and secretion in rats. Indian J Exp Biol 39: 137-142, 2001.

19. Katare SS and Ganachari MS: Effect of Centella asiatica on hypoxia induced convulsions and lithium-pilocarpine induced status epilepticus and antilipid peroxidation activity. Ind J Pharmacol 33: 128, 2001.

20. Jayashree G, Kurup Muraleedhara G, Sudarslal S and Jacob VB: Anti-oxidant activity of Centella asiatica on lymphoma-bearing mice. Fitoterapia 74: 431-434, 2003.

21. Brunt EM: Grading and staging the histopathological lesions of chronic hepatitis: The knodell histology activity index and beyond. Hepatology 31: 241-246, 2000.

22. Miranda KM, Espey MG and Wink DA: A rapid, simple spectrophotometric method for simultaneous detection of nitrate and nitrite. Nitric Oxide 5: 62-71, 2001.

23. Ray SD, Sorge CL, Kamendulis LM and Corcoran GB $\mathrm{Ca}(++)$-activated DNA fragmentation and dimethylnitrosamine-induced hepatic necrosis: Effects of ca (++)-endonuclease and poly (ADP-ribose) polymerase inhibitors in mice. J Pharmaco Exp Ther 263: 387-394, 1992.

24. Saad RA, EL-Bab MF and Shalaby AA: Attenuation of acute and chronic liver injury by melatonin in rats. J Taibah Univ Sci 7: 88-96, 2013

25. Pinzani $\mathrm{M}$ and Rombouts K: Liver fibrosis: From the bench to clinical targets. Dig Liver Dis 36: 231-242, 2004

26. Sallie R, Tredger JM and Williams R: Drugs and the liver. Part 1: Testing liver function. Biopharm Drug Dispos 12: 251-259, 1991.

27. Zimmerman HJ: Hepatotoxicity. Dis Mon 39: 675-787, 1993.

28. Nkosi CZ, Opoku AR and Terblanche SE: Effect of pumpkin seed (Cucurbita pepo) protein isolate on the activity levels of certain plasma enzymes in CCl4-induced liver injury in low-protein fed rats. Phytother Res 19: 341-345, 2005.

29. Lander HM: An essential role for free radicals and derived species in signal transduction. FASEB J 11: 118-124, 1997.

30. Rushmore TH and Kong AN: Pharmacogenomics, regulation and signaling pathways of phase I and II drug metabolizing enzymes. Curr Drug Metab 3: 481-490, 2002.
31. Vendemiale G, Grattagliano I, Caruso ML, Serviddio G, Valentini AM, Pirrelli M and Altomare E: Increased oxidative stress in dimethylnitrosamine-induced liver fibrosis in the rat: Effect of $\mathrm{N}$-acetylcysteine and interferon-alpha. Toxicol Appl Pharmacol 175: 130-139, 2001.

32. Gnanapragasam A, Ebenezar KK, Sathish V, Govindaraju P and Devaki T: Protective effect of Centella asiatica on antioxidant tissue defense system against adriamycin induced cardiomyopathy in rats. Life Sci 76: 585-597, 2004.

33. Gupta YK, Veerendra Kumar MH and Srivastava AK: Effect of Centella asiatica on pentylenetetrazole-induced kindling, cognition and oxidative stress in rats. Pharmacol Biochem Behav 74: 579-585, 2003

34. Haleagrahara $\mathrm{N}$ and Ponnusamy K: Neuroprotective effect of Centella asiatica extract (CAE) on experimentally induced parkinsonism in aged sprague-dawley rats. J Toxicol Sci 35: 41-47, 2010.

35. Jaeschke H: Reactive oxygen and mechanisms of inflammatory liver injury. J Gastroenterol Hepatol 15: 718-724, 2000.

36. Duffield JS, Forbes SJ, Constandinou CM, Clay S, Partolina M, Vuthoori S, Wu S, Lang R and Iredale JP: Selective depletion of macrophages reveals distinct, opposing roles during liver injury and repair. J Clin Invest 115: 56-65, 2005.

37. Ishida Y, Maegawa T, Kondo T, Kimura A, Iwakura Y, Nakamura $S$ and Mukaida N: Essential involvement of IFN-gamma in clostridium difficile toxin A-induced enteritis. J Immunol 172: 3018-3025, 2004.

38. Zoheir KM, Amara AA, Ahmad S, et al: Study of the therapeutic effects of lactobacillus and $\alpha$-lipoic acid against dimethylnitrosamine-induced liver fibrosis in rats. J Genet Eng Biotechnol 12: 135-142, 2014.

39. Thompson K, Maltby J, Fallowfield J, McAulay M, Millward-Sadler $\mathrm{H}$ and Sheron N: Interleukin-10 expression and function in experimental murine liver inflammation and fibrosis. Hepatology 28: 1597-1606, 1998.

40. Dennert G: Cloned lines of natural killer cells. Nature 287 47-49, 1980

41. Trinchieri G: Interleukin-12: A cytokine at the interface of inflammation and immunity. Adv Immunol 70: 83-243, 1998.

42. Zeh HJ III, Hurd S, Storkus WJ and Lotze MT: Interleukin-12 promotes the proliferation and cytolytic maturation of immune effectors: Implications for the immunotherapy of cancer. J Immunother Emphasis Tumor Immunol 14: 155-161, 1993.

43. Hamilton JA: Colony stimulating factors, cytokines and monocyte-macrophages-some controversies. Immunol Today 14 18-24, 1993. 